\title{
FAKTOR RISIKO GEJALA SICK BUILDING SYNDROME PADA PEGAWAI BPPSDM KESEHATAN RI
}

\author{
Siti Saffanah ${ }^{1}$, Rafiah Maharani Pulungan ${ }^{2}$ \\ ${ }^{1}$ Program Studi S-1 Kesehatan Masyarakat, Fakultas Ilmu Kesehatan, \\ Universitas Pembangunan Nasional "Veteran" Jakarta \\ Email: saffanahna2@gmail.com \\ ${ }^{2}$ Program Studi S-1 Kesehatan Masyarakat, Fakultas Ilmu Kesehatan, \\ Universitas Pembangunan Nasional "Veteran” Jakarta \\ Email: rafiah.maharani@gmail.com
}

\begin{abstract}
Abstrak
Sick Building Syndrome merupakan salah satu fenomena masalah kesehatan yang diakibatkan oleh lingkungan kerja yang buruk. Penelitian ini bertujuan untuk menganalisis faktor risiko gejala sick building syndrome pada pegawai BPPSDMK RI. Desain penelitian dengan pendekatan cross sectional. Teknik pemilihan sampel dengan sampling purposive dan besar sampel 53 responden. Metode analisis data menggunakan analisis univariat dan analisis bivariat dengan uji Chi-square. Hasil penelitian menunjukkan bahwa terdapat hubungan antara faktor demografi yaitu faktor umur (p-value 0,014) dan faktor-faktor terkait dengan pekerjaan yaitu faktor sistem ventilasi (kecepatan aliran udara) (p-value 0,036) dengan gejala sick building syndrome pada pekerja. Saran yang dapat diberikan yaitu menyempatkan membuka jendela atau pintu sebelum menggunakan AC, melakukan pemeriksaan kualitas fisik udara secara berkala, mempertimbangkan pergantian penggunaan AC sentral dengan AC lokal ditiap ruang, serta meningkatkan pemeliharaan sistem ventilasi dalam ruangan.
\end{abstract}

Kata Kunci: Sick Building Syndrome, Faktor Risiko

\section{RISK FACTORS SYMPTOMS OF SICK BUILDING SYNDROME IN BPPSDMK RI EMPLOYEES}

\begin{abstract}
Sick Building Syndrome is a health problem caused by a poor work environment. This study aimed to analyze the risk factors for sick building syndrome in employees of BPPSDMK RI. This study is an analytic observational design using a cross-sectional approach. Sample selection by purposive sampling and a sample size of 53 respondents. The data analysis method used univariate analysis and bivariate analysis with the Chi-square test. The results showed that there was a relationship between demographic factors, that is age factors (p-value 0.014) and work-related factors, ventilation system (air flow velocity) ( $p$-value 0.036) with sick building syndrome symptoms in workers. Suggestions that can be given are taking the time to open a window or door before using air conditioning, periodically checking the physical air quality, considering changing the use of central air conditioning with local air conditioners in each room, and increasing maintenance of indoor ventilation systems.
\end{abstract}

Keywords: Sick Building Syndrome, Risk Factors 


\section{PENDAHULUAN}

Sick Building syndrome merupakan salah satu masalah kesehatan yang terdiri dari sekumpulan gejala yang dialami oleh pekerja dalam gedung akibat lingkungan kerja yang berhubungan dengan polusi udara, kualitas udara dalam ruangan dan buruknya ventilasi gedung perkantoran, National Institute of Occupational Safety and Health (NIOSH) pada tahun 1997 menyebutkan bahwa dari 52\% penyakit pernapasan berkaitan dengan Sick Building Syndrome yang diakibatkan oleh buruknya ventilasi gedung dan kinerja air conditioner (AC) yang jarang dibersihkan (ASHRAE, 2001)

Menurut Thad Godish (2009) dalam Nizarofah, D.R (2016), seseorang yang dinyatakan mengalami Sick Building Syndrome jika memiliki keluhan sebanyak kurang lebih 2 atau 3 gejala seperti kelelahan, hidung gatal, tenggorokan kering, sakit kepala, mata gatal, mata pedih, mata merah, bersin, rasa mual, rasa kantuk, kulit gatal atau kulit kering, dalam kurun waktu yang bersamaan. (Nizafaroh, 2016)

Sick Building Syndrome disebabkan oleh banyak faktor diantaranya faktor kimia seperti $\mathrm{CO}, \mathrm{CO}^{2}$, formaldehid, asbes, dan debu, kemudian faktor fisik terkait dengan suhu, kelembaban, kecepatan aliran udara, dan pencahayaan, sementara faktor biologinya dipengaruhi oleh bakteri dan jamur, serta faktor karakteristik individu seperti umur, jenis kelamin, merokok, lama bekerja dan faktor psikososial. (Yulianti, 2012)

Sementara menurut hasil penelitian Fauzi (2015) mengenai hubungan faktor fisik, biologi dan karakteristik individu dengan kejadian Sick Building Syndrome (SBS) pada pegawai di Gedung Pandanaran Kota Semarang pada tahun 2015, menyatakan bahwa bahwa ada hubungan antara pencahayaan dengan hasil $p$-value 0.040 $(p$-value $<0.05)$ dan lama kerja dengan hasil $p$ value sebesar 0,017 (p-value<0,05) dengan kejadian Sick Building Syndrome (SBS) pada pegawai di Gedung Pandanaran Kota Semarang. (Fauzi, 2015)

Dalam penelitian lain, dua faktor karakteristik individu yaitu umur dan jenis kelamin juga termasuk dalam faktor demografi yang memiliki pengaruh hubungan terhadap kejadian Sick Building Syndrome. Hal tersebut diperoleh dari penelitian yang dilakukan oleh
Lisyastuti (2010) yang menyatakan bahwa jenis kelamin wanita memiliki risiko yang lebih besar dibandingkan dengan pria. Sebanyak 70\% dari jumlah karyawan wanita mengalami Sick Building Syndrome. (Lisyastuti, 2010)

Gedung BPPSDM Kesehatan RI merupakan salah satu kantor yang berkonsep sebagai gedung bertingkat sederhana. Gedung yang terdiri dari 8 lantai dan dibangun tanpa konsep gedung hijau pada tahun 2007 ini sudah mulai beroperasi sejak tahun 2009. Kondisi gedung BPPSDM Kesehatan RI ini diketahui memiliki sistem ventilasi yang terdiri dari jendela yang bisa dibuka hanya beberapa dan Air Conditioner (AC). Meskipun pengukuran suhu $\left(23,3^{\circ} \mathrm{C}\right.$ dan $\left.25,4^{\circ} \mathrm{C}\right)$, kelembaban udara $(56,1 \%$, dan $50,5 \%)$, dan debu $\left(23 \mathrm{pm}_{0,5}\right.$ dan $12 \mathrm{pm}_{0,5}$ ), serta tingkat pencahayaan (320 lux dan 234 lux) selalu dilakukan setiap tahun dalam gedung ini oleh Balai Besar Teknik Kesehatan Lingkungan milik Direktorat Kesehatan Lingkungan (Kementerian Kesehatan) dan hasilnya dinyatakan bersifat normal.

Kemungkinan akan terjadinya gejala Sick Building Syndrome yang selanjutnya dapat mengakibatkan timbulnya iritasi pada mata, hidung, tenggorokan dan saluran pernapasan dapat saja terjadi pada pekerja karena dari hasil wawancara awal diketahui bahwa belum pernah ada penelitian mengenai Sick Building Syndrome pada pekerja di BPPSDM Kesehatan RI. Sementara dari wawancara pada bagian poliklinik kesehatan diketahui bahwa pada 1 bulan terakhir, sebagian besar keluhan-keluhan yang dialami oleh pekerja BPPSDM Kesehatan RI seperti hipertensi, batuk, asma, sakit kepala, iritasi mata, gastritis, ISPA dan penyakit lainnya yang merupakan bagian dari gejala Sick Building Syndrome.

Berdasarkan uraian latar belakang tersebut tujuan dari penelitian ini adalah untuk mengalisa hubungan faktor demografi dan faktor-faktor terkait dengan pekerjaan terhadap gejala Sick Building Syndrome (SBS) pada pekerja BPPSDM Kesehatan RI tahun 2017.

\section{METODE PENELITIAN}

Dalam penelitian ini terdapat dua variabel independen yaitu, Faktor Demografi, dan Faktor-faktor Terkait Dengan Pekerjaan. Adapun Faktor Demografi yang diambil dalam penelitian ini yaitu Umur, dan Jenis Kelamin. 
Sementara Faktor-faktor Terkait Dengan Pekerjaan yang diambil dalam penelitian ini yaitu, kualitas udara dalam ruang kerja (Sistem Ventilasi/Kecepatan Aliran Udara, dan Kelembaban) serta Jam Kerja. Selain itu, untuk variabel dependen dalam penelitian ini yaitu Gejala Sick Building Syndrome (SBS).

Penelitian ini menggunakan pendekatan cross sectional yang dilakukan pada bulan April-Juni 2017. Pemilihan sampel pada penelitian ini menggunakan rancangan non probability sampling dengan teknik sampling purposive dengan perhitungan rumus sehingga dihasilkan sampel yang diperlukan sebesar 53 orang. Data primer yang diperoleh dalam penelitian ini dilakukan dengan cara melakukan survey awal dengan melakukan wawancara dan pengukuran kualitas udara di ruang kerja. Sedangkan data sekunder yang diperoleh berupa informasi dari jurnal, internet, dokumen dan data dari instansi yang diperlukan seperti data instansi secara umum, dll. Instrumen yang akan digunakan dalam penelitian ini adalah kuesioner, thermometer hygrometer, dan Anemometer.

\section{HASIL}

a. Gambaran Gejala Sick Building Syndrome, Faktor Demografi dan Faktor Terkait Dengan Pekerjaan pada Responden BPPSDM Kesehatan RI

Tabel 1. Distribusi Gejala Sick Building Syndrome, Faktor Demografi dan Faktorfaktor Terkait Dengan Pekerjaan

\begin{tabular}{|c|c|c|}
\hline Variabel & $\begin{array}{c}\text { Frekuensi } \\
(\mathrm{N})\end{array}$ & $\begin{array}{c}\text { Persenta } \\
\text { se }(\%)\end{array}$ \\
\hline \multicolumn{3}{|c|}{ Gejala Sick Building Syndrome: } \\
\hline TDK SBS & 10 & 18,9 \\
\hline SBS & 43 & 81,1 \\
\hline \multicolumn{3}{|l|}{ Umur } \\
\hline Produktif (25-54 tahun) & 43 & 81,1 \\
\hline Dewasa ( $\geq 55$ tahun) & 10 & 18,9 \\
\hline \multicolumn{3}{|l|}{ Jenis Kelamin: } \\
\hline Laki-laki & 23 & 43,4 \\
\hline Perempuan & 30 & 56,6 \\
\hline \multicolumn{3}{|c|}{$\begin{array}{l}\text { Sistem Ventilasi (Kecepatan } \\
\text { Aliran Udara) }\end{array}$} \\
\hline Tidak Standar & 13 & 81,2 \\
\hline Standar & 3 & 18,8 \\
\hline \multicolumn{3}{|l|}{ Kelembaban Udara: } \\
\hline Tidak Standar & 4 & 25,0 \\
\hline Standar & 12 & 75,0 \\
\hline \multicolumn{3}{|l|}{ Jam Kerja: } \\
\hline 8 jam & 50 & 94,3 \\
\hline$>8$ jam & 3 & 5,7 \\
\hline
\end{tabular}

Hasil gejala sick building syndrome secara keseluruhan pada responden yang didapatkan menunjukkan bahwa gejala sick building syndrome dialami pada sebagian besar responden sebanyak 43 orang $(81,1 \%)$, sedangkan responden yang tidak mengalami gejala sick building syndrome yaitu sebesar 10 orang $(18,9 \%)$, dimana kumpulan gejala sick building syndrome yang paling banyak dialami oleh responden yaitu berupa keluhan pegalpegal yakni 28 responden $(52,8 \%)$, lalu diikuti dengan keluhan seringnya buang air kecil sebanyak 27 responden $(50,9 \%)$, sementara pada urutan ketiga yaitu keluhan sakit dibagian punggung sebesar 25 responden $(47,2 \%)$. Diketahui juga bahwa gejala berupa merahmerah pada kulit tidak ditemukan pada semua responden dalam penelitian ini, karena gejala tersebut tidak pernah dialami oleh semua responden.

Berdasarkan tabel 1 menunjukan bahwa sebagian besar responden termasuk dalam kategori umur produktif sebanyak 43 orang $(81,1 \%)$, sedangkan responden yang memiliki umur yang termasuk dalam kategori dewasa sebesar 10 orang $(18,9 \%)$. Selain itu dapat diketahui juga bahwa jenis kelamin responden terbagi menjadi 2 kategori yaitu laki-laki dan perempuan, dimana sebagian besar responden memiliki jenis kelamin perempuan yang sebesar 30 orang $(56,6 \%)$, sementara responden yang berjenis kelamin laki-laki sebanyak 23 orang $(43,4 \%)$.

\section{b. Hubungan Umur Terhadap Gejala Sick Building Syndrome}

Tabel 2. Hubungan Umur Terhadap Gejala Sick Building Syndrome Pada Responden di BPPSDM Kesehatan RI

\begin{tabular}{|c|c|c|c|c|c|c|c|}
\hline \multirow{3}{*}{ Umur } & \multicolumn{4}{|c|}{ Gejala SBS } & \multirow{2}{*}{\multicolumn{2}{|c|}{ Total }} & \multirow{3}{*}{$\begin{array}{c}P- \\
\text { Value }\end{array}$} \\
\hline & \multicolumn{2}{|c|}{ TDK SBS } & \multicolumn{2}{|c|}{ SBS } & & & \\
\hline & $\mathrm{N}$ & $\%$ & $\mathrm{~N}$ & $\%$ & $\mathrm{~N}$ & $\%$ & \\
\hline $\begin{array}{c}\text { Produktif } \\
(25-54 \\
\text { tahun) }\end{array}$ & 5 & 11,6 & 38 & 88,4 & 43 & 100 & 0,014 \\
\hline $\begin{array}{c}\text { Dewasa } \\
(\geq 55 \text { tahun })\end{array}$ & 5 & 50,0 & 5 & 50,0 & 10 & 100 & \\
\hline
\end{tabular}

Berdasarkan hasil uji statistik dengan menggunakan uji chi-square diperoleh $p$-value sebesar 0,014 atau $p$-value $<$ nilai alpha $(0,05)$ 
sehingga Ho ditolak, maka dapat disimpulkan bahwa ada hubungan yang bermakna antara umur dengan gejala sick building syndrome pada pekerja BPPSDM Kesehatan RI.

\section{c. Hubungan Jenis Kelamin Terhadap Gejala Sick Building Syndrome}

Tabel 3. Hubungan Jenis Kelamin Terhadap Gejala Sick Building Syndrome Pada Responden di BPPSDM Kesehatan RI

\begin{tabular}{|c|c|c|c|c|c|c|c|}
\hline \multirow{3}{*}{$\begin{array}{c}\text { Jenis } \\
\text { Kelamin }\end{array}$} & \multicolumn{4}{|c|}{ Gejala SBS } & \multirow{2}{*}{\multicolumn{2}{|c|}{ Total }} & \multirow{3}{*}{$\begin{array}{c}P- \\
\text { Value }\end{array}$} \\
\hline & \multicolumn{2}{|c|}{ TDK SBS } & \multicolumn{2}{|c|}{ SBS } & & & \\
\hline & $\mathrm{N}$ & $\%$ & $\mathrm{~N}$ & $\%$ & $\mathrm{~N}$ & $\%$ & \\
\hline Laki-laki & 5 & 21,7 & 18 & 78,3 & 23 & 100,0 & \\
\hline Perempuan & 5 & 16,7 & 25 & 83,3 & 30 & 100,0 & \\
\hline
\end{tabular}

Berdasarkan hasil uji statistik yang dilakukan dengan menggunakan uji chi-square diperoleh $p$-value sebesar 0,730 atau $p$-value>nilai alpha $(0,05)$ yang berarti bahwa Ho diterima, sehingga dapat disimpulkan bahwa tidak ada hubungan yang bermakna antara jenis kelamin terhadap gejala sick building syndrome pada pekerja BPPSDM Kesehatan RI.

\section{d. Hubungan Sistem Ventilasi (Kecepatan} Aliran Udara) Terhadap Gejala Sick Building Syndrome

Tabel 4. Tabel 12 Hubungan Sistem Ventilasi (Kecepatan Aliran Udara) Terhadap Gejala Sick Building Syndrome Pada Pekerja BPPSDM Kesehatan RI

\begin{tabular}{|c|c|c|c|c|c|c|c|}
\hline \multirow{3}{*}{$\begin{array}{c}\text { Sistem } \\
\text { Ventilasi }\end{array}$} & \multicolumn{4}{|c|}{ Gejala SBS } & \multirow{2}{*}{\multicolumn{2}{|c|}{ Total }} & \multirow{3}{*}{ P-Value } \\
\hline & \multicolumn{2}{|c|}{ TDK SBS } & \multicolumn{2}{|c|}{ SBS } & & & \\
\hline & $\mathrm{N}$ & $\%$ & $\mathrm{~N}$ & $\%$ & $\mathrm{~N}$ & $\%$ & \\
\hline $\begin{array}{l}\text { Tidak } \\
\text { Standar }\end{array}$ & 5 & 12,2 & 36 & 87,8 & 41 & 100,0 & \multirow{2}{*}{0,036} \\
\hline Standar & 5 & 41,7 & 7 & 58,3 & 12 & 100,0 & \\
\hline
\end{tabular}

Berdasarkan hasil uji statistik yang dilakukan berdasarkan penggunaan uji chisquare dan diperoleh p-value yakni sebesar 0,036 atau $p$-value <nilai alpha $(0,05)$ maka Ho ditolak. Dengan demikian dapat disimpulkan bahwa ada hubungan yang bermakna antara sistem ventilasi (kecepatan aliran udara) terhadap gejala sick building syndrome pada pekerja BPPSDM Kesehatan RI.

\section{e. Hubungan Kelembaban Udara Terhadap Gejala Sick Building Syndrome}

Tabel 5. Hubungan Kelembaban Udara Terhadap Gejala Sick Building Syndrome Pada Pekerja BPPSDM Kesehatan RI

\begin{tabular}{|c|c|c|c|c|c|c|c|}
\hline \multirow{3}{*}{$\begin{array}{c}\text { Kelembaban } \\
\text { Udara }\end{array}$} & \multicolumn{4}{|c|}{ Gejala SBS } & \multirow{2}{*}{\multicolumn{2}{|c|}{ Total }} & \multirow{3}{*}{$\begin{array}{c}P- \\
\text { Value }\end{array}$} \\
\hline & \multicolumn{2}{|c|}{ TDK SBS } & \multicolumn{2}{|c|}{ SBS } & & & \\
\hline & $\mathrm{N}$ & $\%$ & $\mathrm{~N}$ & $\%$ & $\mathrm{~N}$ & $\%$ & \\
\hline Tidak Standar & 1 & 5,9 & 16 & 94,1 & 17 & 100,0 & \\
\hline Standar & 9 & 25,0 & 27 & 75,0 & 36 & 100,0 & \\
\hline
\end{tabular}

Berdasarkan hasil uji statistik dengan penggunaan uji chi-square diperoleh p-value $(0,140)>$ nilai alpha $(0,05)$ sehingga menyatakan bahwa Ho diterima, maka dapat disimpulkan bahwa tidak ada hubungan yang bermakna antara kelembaban udara terhadap gejala sick building syndrome pada pekerja BPPSDM Kesehatan RI.

\section{f. Hubungan Jam Kerja Terhadap Gejala Sick Building Syndrome}

Tabel 6. Hubungan Jam Kerja Terhadap Gejala Sick Building Syndrome Pada Pekerja BPPSDM Kesehatan RI

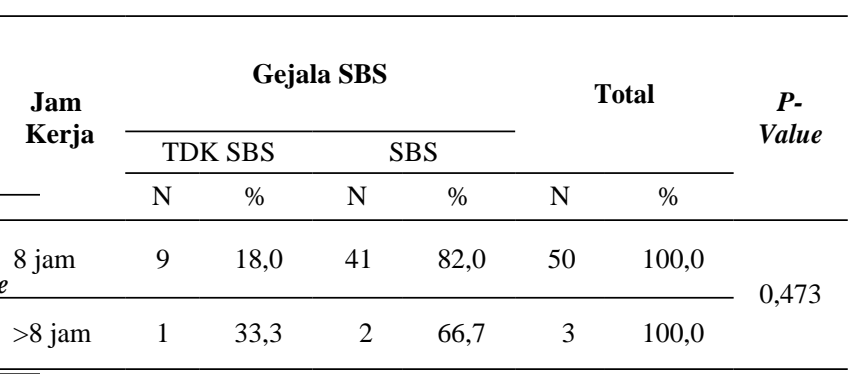

Berdasarkan hasil uji statistik dengan menggunakan uji chi-square diperoleh nilai $p$ value sebesar 0,473 atau $p$-value $>$ nilai alpha maka Ho diterima, sehingga dapat disimpulkan bahwa tidak ada hubungan yang bermakna antara jam kerja terhadap gejala sick building syndrome pada pekerja BPPSDM Kesehatan RI. 


\section{PEMBAHASAN}

\section{a. Gambaran Gejala Sick Building Syndrome, Faktor Demografi dan Faktor Terkait Dengan Pekerjaan pada Responden BPPSDM Kesehatan RI}

Hasil gejala sick building syndrome secara keseluruhan pada responden yang didapatkan menunjukkan bahwa gejala sick building syndrome dialami pada sebagian besar responden sebanyak 43 orang $(81,1 \%)$, sedangkan responden yang tidak mengalami gejala sick building syndrome yaitu sebesar 10 orang (18,9\%), dimana kumpulan gejala sick building syndrome yang paling banyak dialami oleh responden yaitu berupa keluhan pegalpegal yakni 28 responden $(52,8 \%)$, lalu diikuti dengan keluhan seringnya buang air kecil sebanyak 27 responden (50,9\%), sementara pada urutan ketiga yaitu keluhan sakit dibagian punggung sebesar 25 responden $(47,2 \%)$. Diketahui juga bahwa gejala berupa merahmerah pada kulit tidak ditemukan pada semua responden dalam penelitian ini, karena gejala tersebut tidak pernah dialami oleh semua responden.

Berdasarkan tabel 1 menunjukan bahwa sebagian besar responden termasuk dalam kategori umur produktif sebanyak 43 orang $(81,1 \%)$, sedangkan responden yang memiliki umur yang termasuk dalam kategori dewasa sebesar 10 orang $(18,9 \%)$. Selain itu dapat diketahui juga bahwa jenis kelamin responden terbagi menjadi 2 kategori yaitu laki-laki dan perempuan, dimana sebagian besar responden memiliki jenis kelamin perempuan yang sebesar 30 orang $(56,6 \%)$, sementara responden yang berjenis kelamin laki-laki sebanyak 23 orang $(43,4 \%)$.

Berdasarkan hasil pengukuran kecepatan aliran udara, diperoleh nilai kecepatan aliran udara yang ada pada ruang kerja responden diketahui terdapat 13 lokasi yang tidak memenuhi standar menurut Peraturan Menteri Kesehatan Republik Indonesia Nomor 48 tahun 2016 yaitu $0,15 \mathrm{~m} /$ detik-0,25 m/detik, diantaranya yaitu 302, 304, 313, 314, 401, 404, 503, 504, 505, 517, 602, 603, dan 702 karena nilainya ada yang kurang dari $0,15 \mathrm{~m} /$ detik dan lebih dari $0,25 \mathrm{~m} /$ detik, sedangkan 3 lokasi sisanya yaitu 306, 317, dan 509 telah sesuai dengan standar Peraturan Menteri Kesehatan Republik Indonesia Nomor 48 Tahun 2016.(Kemenkes, 2016)

Sementara berdasarkan hasil penelitian menunjukkan bahwa distribusi terbesar terdapat pada responden yang bekerja pada ruang kerja dengan kecepatan aliran udara yang tidak sesuai dengan standar yaitu sebesar 13 lokasi $(81,2 \%)$, sedangkan distribusi responden yang bekerja pada ruang kerja dengan kelembaban udara yang sesuai dengan standar hanya terdapat pada 3 lokasi $(18,8 \%)$.

Selain itu, berdasarkan hasil pengukuran kelembaban udara diketahui bahwa terdapat 12 lokasi yang merupakan ruang kerja responden yang memiliki nilai kelembaban udara yang sesuai dengan standar kelembaban di tempat kerja menurut Peraturan Menteri Kesehatan Republik Indonesia Nomor 48 tahun 2016 yaitu 40\%-60\%, dimana 12 lokasi tersebut yaitu 302, 304, 313, 317, 404, 503, 504, 505, 509, 602, 603 , dan 702. Sementara sisanya yaitu 4 lokasi yang terdiri dari lokasi 306, 314, 401, dan 517 termasuk dalam kategori ruang kerja yang tidak memenuhi standar kelembaban udara karna hasil pengukurannya melebihi angka $60 \%$.

Berdasarkan hasil penelitian menunjukkan bahwa persentase distribusi terbesar terdapat pada responden yang bekerja pada ruang kerja dengan kelembaban udara yang tidak sesuai dengan standar sebesar 12 lokasi $(75,0 \%)$ sedangkan distribusi responden yang bekerja pada ruang kerja dengan kelembaban udara yang sesuai dengan standar sebanyak 4 lokasi $(25,0 \%)$.

Berdasarkan tabel 1 diketahui juga bahwa distribusi terbesar jam kerja responden terdapat pada responden dengan jam kerja 8 jam yaitu sebesar 50 orang $(94,3 \%)$, sedangkan distribusi responden yang termasuk dalam kategori kedua dengan jam kerja $>8$ jam hanya sebesar 3 orang $(5,7 \%)$.

\section{b. Hubungan Umur Terhadap Gejala Sick Building Syndrome}

Berdasarkan hasil uji statistik dengan menggunakan uji chi-square diperoleh $p$-value sebesar 0,014 atau $p$-value <nilai alpha $(0,05)$ sehingga Ho ditolak, maka dapat disimpulkan bahwa ada hubungan yang bermakna antara umur dengan gejala sick building syndrome pada pekerja BPPSDM Kesehatan RI. 


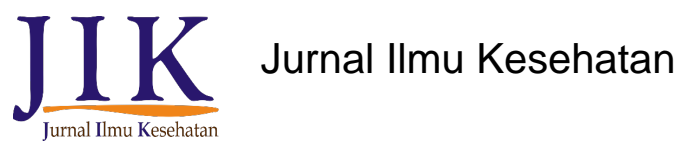

Hal ini sejalan dengan hasil penelitian Laila (2011) yang menyimpulkan bahwa umur sangat mempengaruhi tingkat resiko dalam terjadinya suatu penyakit yang berkaitan dengan pekerjaan, salah satunya termasuk kejadian sick building syndrome. Dimana hal tersebut dapat disebabkan karena ketika seseorang berusia produktif biasanya pekerja dituntut untuk menunjukkan performa kerja yang optimal, sehingga stamina yang ada pun dapat menurun (Laila, 2016)

Hasil penelitian yang dikemukakan oleh Laila (2011) tersebut tidak sejalan dengan hasil penelitian lain yang dilakukan oleh Fauzi (2014) pada pekerja di Gedung Pandanaran Kota Semarang, dimana tidak ada hubungan antara umur yang menjadi faktor karakteristik individu dengan kejadian sick building syndrome karena nilai p-value 0,093>0,05. (Laila, 2016)

\section{c. Hubungan Jenis Kelamin Terhadap Gejala Sick Building Syndrome}

Berdasarkan hasil uji statistik yang dilakukan dengan menggunakan uji chi-square diperoleh $p$-value sebesar 0,730 atau $p$ value>nilai alpha $(0,05)$ yang berarti bahwa Ho diterima, sehingga dapat disimpulkan bahwa tidak ada hubungan yang bermakna antara jenis kelamin terhadap gejala sick building syndrome pada pekerja BPPSDM Kesehatan RI.

Hasil penelitian tersebut sesuai dengan hasil penelitian yang dilakukan oleh Raharjo (2015) yang menunjukkan bahwa didapatkan hasil pvalue (sig.) sebesar 0,270, dimana $p>0,05$ maka artinya dapat disimpulkan tidak terdapat pengaruh antara jenis kelamin dengan gejala SBS pada pegawai gedung utama Perusahaan Fabrikasi Kapal, dimana penderita SBS Sebagian besar responden berjenis kelamin pria yaitu 67,74 sedangkan responden berjenis kelamin wanita yaitu 32,26\%.(Raharjo, 2016)

Namun hasil penelitian tersebut tidak sejalan dengan hasil penelitian Zaelani (2015) yang menyatakan bahwa jenis kelamin merupakan salah satu variabel yang menunjukkan adanya hubungan yang penting dalam terjadinya Sick Building Syndrome dengan $p$-value $(0,037)<$ nilai alpha $(0,05)$. (Zaelani, 2015)

Beberapa peneliti lainnya yang mendukung hasil penelitian Zaelani (2015) tersebut diantaranya yakni Rahman dkk (2013) dalam jurnalnya yang menyatakan bahwa jenis kelamin laki-laki lebih berpengaruh dalam terjadinya Sick building syndrome dengan persentase sebesar 29 responden $(43,9 \%)$ dari pada jenis kelamin perempuan yang hanya 9 responden (34,6\%). (Rahman, Naiem, \& Russeng, 2014)

\section{d. Hubungan Sistem Ventilasi (Kecepatan Aliran Udara) Terhadap Gejala Sick Building Syndrome}

Berdasarkan hasil uji statistik yang dilakukan berdasarkan penggunaan uji chisquare dan diperoleh p-value yakni sebesar 0,036 atau $p$-value <nilai alpha $(0,05)$ maka Ho ditolak. Dengan demikian dapat disimpulkan bahwa ada hubungan yang bermakna antara sistem ventilasi (kecepatan aliran udara) terhadap gejala sick building syndrome pada pekerja BPPSDM Kesehatan RI.

Hasil penelitian ini sejalan dengan hasil penelitian yang dilakukan oleh Aryanti (2016) yang menyatakan bahwa laju udara memiliki hubungan yang bermakna dengan keluhan sick building syndrome karena p-value yang diperoleh yaitu 0,037>0,05. (Aryanti, 2016) Namun, hasil penelitian tersebut tidak sejalan dengan hasil penelitian yang dilakukan oleh Juarsih (2013), dimana tingkat kecepatan udara tidak terdapat adanya hubungan yang signifikan terhadap sick building syndrome dengan nilai $p=0,192>0,05$. (Juarsih, 2013)

\section{e. Hubungan Kelembaban Udara Terhadap Gejala Sick Building Syndrome}

Berdasarkan hasil uji statistik dengan penggunaan uji chi-square diperoleh p-value $(0,140)>$ nilai alpha $(0,05)$ sehingga menyatakan bahwa Ho diterima, maka dapat disimpulkan bahwa tidak ada hubungan yang bermakna antara kelembaban udara terhadap gejala sick building syndrome pada pekerja BPPSDM Kesehatan RI. Hasil penelitian ini sesuai dengan hasil analisis dalam penelitian Juarsih (2013) yang menunjukkan bahwa tingkat kelembaban udara tidak memiliki pengaruh terhadap kejadian sick building syndrome dengan nilai $p=0,192>0,05$.

\section{f. Hubungan Jam Kerja Terhadap Gejala Sick Building Syndrome}

Berdasarkan hasil uji statistik dengan menggunakan uji chi-square diperoleh nilai $p$ value sebesar 0,473 atau $p$-value $>$ nilai alpha maka Ho diterima, sehingga dapat disimpulkan 


\section{$\mathrm{JIKK}$

bahwa tidak ada hubungan yang bermakna antara jam kerja terhadap gejala sick building syndrome pada pekerja BPPSDM Kesehatan RI. Hasil penelitian tersebut sejalan dengan hasil penelitian yang dilakukan oleh Fauzi (2015) yang juga menunjukkan hasil penelitian yang diketahui bahwa lama kerja memiliki hubungan yang bermakna dengan kejadian sick building syndrome dengan $p$-value $0,017<0,05$.

\section{SIMPULAN}

Berdasarkan hasil penelitian yang telah dilakukan mengenai hubungan faktor demografi dan faktor-faktor terkait dengan pekerjaan terhadap gejala Sick Building Syndrome (SBS) pada pekerja BPPSDM Kesehatan RI tahun 2017, dapat diambil kesimpulan sebagai berikut:

a. Ada hubungan yang bermakna antara umur pekerja terhadap gejala sick building syndrome pada pekerja BPPSDM Kesehatan RI.

b. Tidak ada hubungan yang bermakna antara jenis kelamin pekerja terhadap gejala sick building syndrome pada pekerja BPPSDM Kesehatan RI.

c. Ada hubungan yang bermakna antara sistem ventilasi (kecepatan aliran udara) dalam ruang kerja terhadap gejala sick building syndrome pada pekerja BPPSDM Kesehatan RI.

d. Tidak ada hubungan yang bermakna antara kelembaban udara pada ruang kerja terhadap gejala sick building syndrome pada pekerja BPPSDM Kesehatan RI.

e. Tidak ada hubungan yang bermakna antara jam kerja pekerja terhadap gejala sick building syndrome pada pekerja BPPSDM Kesehatan RI.

\section{SARAN}

Berdasarkan kesimpulan diatas, saran yang dapat menjadi bahan pertimbangan untuk pihak-pihak terkait dalam mengatasi masalah kesehatan berupa gejala sick building syndrome dapat dilakukan penatalaksaan terkait, diantaranya sebagai berikut:

a. Dianjurkan untuk dilakukan pemeriksaan kualitas fisik udara dalam ruang kerja seperti kelembaban dan kecepatan aliran udara secara berkala sehingga dapat melakukan upaya pencegahan agar terhindar dari gejala sick building syndrome. b. Melakukan pemberdayaan bagi seluruh manajer dan pekerja untuk dapat meningkatkan kebersihan lingkungan kerja melalui penataan ruangan kerja, penataan arsip dan berkas dalam tempat tertutup sesudah bekerja agar menghindari terjadinya penumpukan debu, serta menjaga kebersihan peralatan kerja dengan membersihkan ruangan setiap hari dan perangkat AC secara berkala.

c. Melakukan perbaikan kecepatan aliran udara pada sistem ventilasi untuk mengatasi gejala sick building syndrome yang terjadi seperti dengan mempertimbangkan penggunaan $\mathrm{AC}$ sentral dengan menggantinya dengan $\mathrm{AC}$ lokal yang sifatnya dapat diatur sesuai dengan kebutuhan masing-masing pekerja tiap ruang atau lokasi.

d. Diperlukan peningkatan pemeliharaan terhadap sistem ventilasi yang digunakan baik yang berupa AC sentral maupun jendela pada tiap ruangan.

e. Perlu diadakan dan diterapkannya program terkait dengan monitoring kesehatan, seperti dengan melaksanakan pemeriksaan kesehatan secara berkala agar dapat mendeteksi dan mengetahui sejak dini gangguan ke sehatan yang terjadi pada pekerja.

a. Bagi Pekerja

1) Sebaiknya pekerja di BPPSDM Kesehatan RI sebelum menggunakan Air Conditioner (AC) menyempatkan untuk membuka jendela atau pintu terlebih dahulu selama 15-20 menit, serta menjaga kebersihan udara dalam ruang kerja masing-masing.

2) Melakukan refleksi dengan keluar ruangan 10-15 menit untuk menghirup udara segar dan merelaksasikan otot-otot tubuh sehingga tidak cepat lelah dan mudah mengalami Sick Building Syndrome.

\section{UCAPAN TERIMA KASIH}

Terima kasih kepada Kepala Bagian Kepegawaian dan Umum Badan dan seluruh pegawai Pengembangan dan Pemberdayaan Sumber Daya Manusia Kesehatan Kementerian Kesehatan Republik Indonesia telah memberikan izin sebagai tempat penelitian. 


\section{DAFTAR PUSTAKA}

Aryanti, H. . (2016). Faktor-Faktor Yang Berhubungan Dengan Keluhan Sick Building Syndrome Pada Karyawan Bank Papua Cabang Jakarta Pusat Tahun 2016. Universitas Pembangunan Nasional Veteran Jakarta.

ASHRAE. (2001). Ventilation for Acceptable Indoor Air Quality (Vol. 2001). American Society of Heating, Refrigerating and AirConditioning Engineers, Inc.

Fauzi, M. (2015). Hubungan Faktor Fisik, Biologi dan Karakteristik Individu Dengan Kejadian Sick Building Syndrome pada Pegawai di Gedung Pandanaran Kota Semarang.

Juarsih. (2013). Pengaruh Kualitas Fisik Udara Dalam Ruangan Ber AC Terhadap Kejadian Sick Building Syndrome (SBS) Pada Pegawai Di Gedung Pusat Teknologi Informasi Dan Komunikasi (PUSTIKOM) Universitas Negeri Gorontalo. Universitas Gorontalo.

Kemenkes. Peraturan Menteri Kesehatan Republik Indonesia Nomor 48 Tahun 2016, Peraturan Menteri Kesehatan Republik Indonesia tentang standar keselamatan dan kesehatan kerja perkantoran (2016).

Laila, N. N. (2016). Faktor-Faktor Yang Berhubungan Dengan Keluhan Sick Building Syndrome (SBS) Pada Pegawai Di Gedung Rektorat Syarif Hidayatullah Jakarta Tahun 2011. Universitas Islam Negeri Syarif Hidayatullah Jakarta.

Lisyastuti, E. S. I. (2010). Jumlah koloni mikroorganisme udara dalam ruang dan hubungannya dengan kejadian. Tesis, 1-55. Retrieved from http://lib.ui.ac.id/file?file=digital/2030037 3-T 30520-Jumlah koloni-full text.pdf

Nizafaroh. (2016). Faktor-Faktor Yang Berhubungan Dengan Kejadian Sick Building Syndrome Pada Pekerja Di PT Sai Apparel Industries Semarang. Universitas Muhammadiyah Semarang.

Raharjo, H. D. (2016). Analisis Pengaruh Karakteristik Individu dan Faktor Fisik Terhadap Gejala Sick Building Syndrome Pada Pegawai di Gedung Utama Perusahaan Fabrikasi Kapal. In
Proceeding 1st Conference on Safety Engineering and Its Application.

Rahman, N. H., Naiem, F., \& Russeng, S. (2014). Studi tentang Keluhan Sick Building Syndrome (SBS) pada Pegawai di Gedung Rektorat Universitas Hasanuddin Makassar. Artikel, 1-12. Retrieved from http://repository.unhas.ac.id/bitstream/han dle/123456789/8529/Jurnal Studi Tentang Keluhan Sick Building Syndrome.pdfsequence $=1$

Yulianti. (2012). Sick Building Syndrome. Jurnal CDK-189, 39 no.

Zaelani, A. (2015). Faktor-faktor yang Mempengaruhi Kejadian Sick Building syndrome pada Pegawai di Departemen Distribusi Wilayah 1 Graha Sarana PT $>$ Petrokimia Gresik. Retrieved from http://repository.unej.ac.id/ 